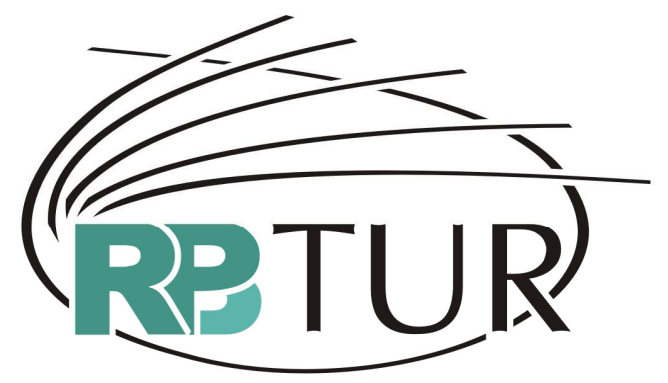

REVISTA BRASILEIRA DE PESQUISA EM TURISMO

\title{
FATORES DE INFLUÊNCIA NO INTERESSE EMPREENDEDOR: UMA ANÁLISE JUNTO A ESTUDANTES DE TURISMO
}

\author{
INFLUENCING FACTORS TO BE INTERESTED IN \\ ENTREPRENEURIAL ACTIVITIES: AN ANALYSIS WITH TOURISM \\ STUDENTS
}

Francisco José da Costa ${ }^{1}$

Resumo: O propósito desta pesquisa foi analisar o interesse empreendedor de estudantes de cursos da área de Turismo. Foi procedida uma revisão de literatura, a partir da qual quatro hipóteses sobre os condicionantes do interesse empreendedor foram enunciadas. Foi desenvolvido um estudo de campo, com dados coletados junto a 149 estudantes de instituições de ensino superior de Fortaleza. Os dados foram avaliados por meio de análise descritiva e das técnicas análise de regressão, e de variância. Verificou-se que: (1) os estudantes, em geral, têm uma predisposição intermediária para empreender; (2) o interesse empreendedor é influenciado pela vocação empreendedora percebida na área, pelo suporte de amigos e familiares, pela posse de empresa na família, e pela percepção de domínio das habilidades empreendedoras de nível estratégico. Os resultados foram limitados pela amostragem não probabilística, mas trazem indicações para a melhoria das ações de incentivo ao empreendedorismo realizadas para estudantes de cursos da área de Turismo.

Palavras-chave: Empreendedorismo. Interesse empreendedor. Estudantes de Turismo.

Abstract: This research intends to analyze the interest students attending Tourism Programmes have in entrepreneurial activities. A bibliographical research was conducted and four hypotheses were announced. Data were collected during a field study with 149 students of higher education institutions located at Fortaleza (Ceara State, Brazil). Data were analyzed using three statistical techniques: descriptive analysis, multiple regression analysis, and analysis of variance. It was found that: (1) students, in general, have an intermediary predisposition to engage in entrepreneurial activities; (2) entrepreneurial interest is influenced by the perceived entrepreneurial vocation of the area, support of friends and family, ownership of a firm (individual or family business), and the perceived mastership of entrepreneurial strategic skills. Even results have limitations due to non-probabilistic sampling, they may help to improve the actions developed to encourage entrepreneurial interest in tourism students.

Key words: Entrepreneurship. Entrepreneurial interest. Tourism students.

\footnotetext{
${ }^{1}$ Doutor em Administração e pesquisador do Convênio CNPq/FUNCAP, atuando no Mestrado Acadêmico em Administração da Universidade Estadual do Ceará. Email: franzecosta@gmail.com
} 


\section{Introdução}

A formação profissional nos cursos superiores das mais diversas áreas teve, nos últimos 15 anos, fortes modificações, por influência, entre outros motivos, da alternativa do empreendedorismo para os futuros profissionais. Vários cursos das áreas de Ciências Sociais Aplicadas (como Administração, Contabilidade e Turismo) e das áreas de Tecnologia da Informação (como Ciência da Computação, Sistemas de Informação, Engenharia de Software), passaram a contar com uma disciplina diretamente associada ao empreendedorismo, e com orientação para a construção dos requisitos necessários à iniciativa de abertura de novos negócios.

O modelo de formação com ênfase no empreendedorismo pareceu uma interessante opção para os cursos, uma vez que possibilita aliar o conhecimento teórico adquirido nos cursos com a exploração de oportunidades de mercado, formando um profissional orientado para além da cultura do emprego (CHIAVENATO, 2006).

A crença central é de que a orientação dada ao empreendedorismo pelas instituições (por meio de disciplinas específicas, por projetos como empresas juniores ou incubadoras, por exemplo) tem um potencial (teórico) de orientar os profissionais para empreender na medida em que viabilizam a vivência das experiências necessárias aos futuros empresários. Por outro lado, os estudos exploratórios realizados para esta pesquisa não indicaram os resultados efetivos desta orientação e destas ações.

Acredita-se que as ações destas instituições tenham um impacto principalmente na construção de habilidades empreendedoras, tanto de natureza estratégica (como visão de novos negócios, captação de oportunidades...), quanto operacionais (para o gerenciamento do dia-a-dia do negócio). Por outro lado, aqui parte-se do pressuposto de que o atendimento aos requisitos de habilidades, a despeito de sua relevância para o sucesso dos 
negócios, tem potencial limitado na construção do interesse em empreender de futuros profissionais. Aspectos como o ambiente nacional (BEGLEY; TAN, 2001), as relações sociais (GREVE; SALAFF, 2003), e o condicionamento familiar (MILLER, 2000), dentre outros, são exemplos de condicionamentos que as instituições de formação têm um limitado poder de influência.

Considerando estas possibilidades, definiram-se como tópicos de análise neste estudo a 'orientação percebida' da área de formação para o empreendedorismo, os condicionantes sociais de 'suporte' (de família e de amigos), e o 'domínio' dos requisitos empreendedores. Nestes termos, foi definido como problema central desta pesquisa o seguinte: como estes fatores (orientação, suporte e domínio) influenciam o interesse empreendedor de estudantes de cursos de formação superior?

A proposição deste estudo é dirigida inicialmente aos estudantes, uma vez que estes serão os futuros profissionais das áreas nas quais estão se formando. Dada a dificuldade de abranger as diversas áreas de formação existentes, este trabalho manteve foco em estudantes de cursos da área de Turismo.

A principal justificativa para esta escolha decorre do fato deste curso ser, em uma análise a priori, bastante orientado para o empreendedorismo, especialmente em função do potencial que as habilidades técnicas desenvolvidas neste oferece. Adicionalmente, o setor de Turismo constitui um dos setores que mais geram oportunidades empreendedoras, em razão da diversidade de campos de atuação possíveis para os profissionais da área. As alternativas de negócios em agências de Turismo, escritórios de assessoria e consultoria para o setor público, empresas de eventos, empreendimentos da área de hotelaria e alimentação, dentre outros, são ilustrativos destas possibilidades (GORINI; MENDES, 2005; BENI, 2007).

Conforme defende Ansarah (2001), a formação profissional em Turismo deve orientar-se para a formação de capacidade criativa e pela capacidade de usar e inserir inovações no setor. A visão da autora reforça a importância de uma visão inovadora para os cursos de Turismo, o que se alcança a partir de 
uma orientação mais empreendedora de profissionais atuais e futuros.

Esta realidade realça a grande relevância e utilidade que o espírito empreendedor tem para a área de Turismo, e justifica a incorporação de disciplinas de empreendedorismo nas grades curriculares de muitos cursos superiores da área.

Nestes termos, o objetivo geral da pesquisa ficou assim definido: analisar, no contexto de cursos de Turismo, os fatores de influência no interesse empreendedor dos estudantes. Os objetivos específicos foram: compreender a forma de influência específica de cada um dos fatores selecionados sobre o interesse empreendedor dos estudantes; e avaliar as variações destes fatores considerando cada curso e as variáveis sócioeconômicas dos estudantes.

Para responder a questão de pesquisa colocada e atender aos objetivos definidos, o restante do trabalho foi dividido em quatro partes: a parte seguinte traz a revisão de literatura, com ênfase nos tópicos definidos para a pesquisa; na terceira parte, apresentam-se as decisões e os procedimentos metodológicos adotados no trabalho de campo desenvolvido; a quarta parte traz os resultados e as análises dos dados coletados em campo; por último, são tecidas as considerações finais do estudo, com a discussão dos resultados, e algumas limitações e recomendações para futuras pesquisas.

\section{Revisão teórica}

A atividade empreendedora pode ser entendida como a capacidade do ser humano em moldar as condições ambientais em seu favor, através de um processo visionário de criação da realidade. Segundo Murphy, Liao e Welsch (2006), o incremento da atividade empreendedora é um dos responsáveis pelo aumento de renda per capita no ocidente, especialmente a partir do século $\mathrm{XIX}^{2}$.

2 Conforme Murphy, Liao e Welsch (2006), o empreendedorismo está associado a diversos fenômenos relacionados ao desenvolvimento do comercio internacional, curvas de demanda, competição como mecanismo de inovação e oportunidades de construção. 
A delimitação do campo de estudo do empreendedorismo pode ser atribuída ao trabalho seminal de Schumpeter (1934). Em seu texto, o autor faz uma distinção entre proprietário e empresário, sendo este último associado à idéia de empreendedor, ou seja, a pessoa que inicia um novo negócio. Schumpeter (1934) trabalha com o conceito de destruição criativa, na qual novas práticas substituem outras, as quais se tornam obsoletas. A partir deste entendimento, o autor aponta algumas formas de inovação, como o desenvolvimento de novos produtos, novas formas de organização da produção (incluindo a utilização de novas matérias-primas), e inovações na comercialização e distribuição (as quais incluem acesso a novos mercados). Tais formas de inovação constituem-se, em sua totalidade, as possibilidades de alteração do padrão produtivo.

Sob esta perspectiva, o empreendedorismo se daria a partir de alterações no mercado, através das oportunidades de inovação geradas pelas disfunções do sistema produtivo. A perspectiva de Schumpeter constitui o que ficou reconhecido como corrente economicista do pensamento empreendedor (SOUZA; GUIMARÃES, 2005).

Todavia, diversos outros autores voltaram-se para a análise da relação entre as características pessoais e a atividade empreendedora, o que convencionalmente ficou entendido como a corrente comportamental. O pressuposto desta corrente é de que as pessoas buscam sua realização pessoal, e têm na iniciativa empreendedora um caminho para este objetivo (SOUZA; GUIMARÃES, 2005).

As duas perspectivas (economicista e comportamental) estão centradas na personificação do empreendedor, podendo ser entendidas em um modelo comum pelo sentido da complementaridade, pois, cabe ao empreendedor, condicionado por características especificas (base comportamental), buscar a identificação de oportunidades de mercado e propor ofertas inovadoras para aproveitar estas oportunidades (base economicista).

Apesar da forte referência nestas duas correntes, estudos mais recentes acerca do empreendedorismo têm sua atenção dirigida ao contexto social, 
como a influência de agentes sociais próximos ao empreendedor (como amigos e família), e ambiental (como as normas nacionais), ou o contexto geral de convivência cotidiana do empreendedor (ambiente profissional, área de formação...).

Pode-se entender que estas perspectivas convergem no objetivo de compreender mais adequadamente o processo empreendedor, como forma de identificação e compreensão dos fatores de influência no interesse empreendedor, e na atividade empreendedora em si. $O$ item seguinte se detém nestes tópicos.

\subsection{Tópicos da pesquisa}

A iniciativa empreendedora tem sido objeto de intenso debate, tanto no contexto acadêmico (em nível de pesquisa) como no delineamento de políticas públicas. Para qualquer dos contextos, um dos desafios centrais é compreender as motivações básicas para o interesse das pessoas na atividade empreendedora.

Em um primeiro nível, o interesse empreendedor pode ser explicado pela vertente comportamental do empreendedorismo, que enfatiza a motivação pela busca de auto-realização. Também se pode compreender a motivação por necessidade (falta de alternativa para o trabalho), fato que ocorre em especial para o contexto dos países em desenvolvimento. O primeiro motivo consiste na externalização do eu interior, enquanto que o segundo é mais uma alternativa na busca por uma colocação profissional (DOLABELA, 1999).

Filion $(1999,2001)$ defende que as profissões no futuro terão uma maior inclinação empreendedora, o que direciona a concepção de diferentes tipos de empreendedorismo. Assim, podem-se citar como exemplos das diferentes possibilidades: aqueles que empreendem quando montam a sua própria empresa (empresarial); os que empreendem nas empresas em que são empregados (intra-empreendedorismo); e mais recentemente, destacam-se os empreendedores sociais, os empreendedores ambientais e empreendedores 
institucionais (que atuam nas relações entre empresas).

Para o atendimento dos objetivos deste artigo é necessária a análise dos fatores de influência sobre o interesse empreendedor. No trabalho de Baughn et al (2006), foram analisados os seguintes fatores (cf. item 1.3): influência do contexto, que os autores operacionalizaram como vocação dos países ao empreendedorismo; capital social; e domínio das habilidades empreendedoras. Estes fatores serviram de base para as análises aqui desenvolvidas, conforme exposto a seguir.

Quanto à influência do contexto, levando-se em conta as diferentes áreas de formação de estudantes de ensino superior (e não o contexto nacional, como fizeram Baughn et al [2006]), o entendimento vigente é de que o empreendedorismo constitui-se em uma lógica transversal a diferentes áreas de conhecimento. A experiência e os contatos exploratórios dão indicações de que algumas áreas apresentam maior vocação para o desenvolvimento da atividade empreendedora, como Administração, Engenharias e cursos da área tecnológica, ao passo que outras são mais orientadas ao emprego (como as licenciaturas, por exemplo).

Segundo Araújo et al (2005), as universidades, tanto no Brasil como no exterior, têm passado por uma 'segunda evolução', a partir da adoção da busca de desenvolvimento social e econômico como parte de seus objetivos. Assim, segundo os autores, além da transição para a incorporação da pesquisa na prática de ensino (primeira evolução), surge uma nova função chamada 'universidade empreendedora', o que implica em uma integração do ensino e da pesquisa com o desenvolvimento econômico e social, o que seria viável a partir da disseminação da cultura empreendedora.

Os autores (ARAÚjO et al, 2005), a partir dos dados de uma pesquisa com instituições de ensino superior canadenses, identificaram uma concentração do ensino empreendedor em poucas áreas (mais da metade das disciplinas de empreendedorismo estão em cursos da área de gestão, e em menor escala vêm os cursos da área de engenharia). Os autores não trazem dados nacionais, mas é possível crer que a realidade brasileira seja parecida. A 
justificativa para esta realidade é, acredita-se, o fato destas áreas (gestão e engenharia) serem mais vocacionadas ao empreendedorismo do que as demais.

Quanto ao capital social, este foi entendido como o suporte de pessoas mais próximas do (potencial) empreendedor, ou seja, família e amigos. Pela revisão da literatura, chegou-se a conclusão de que a atividade empreendedora sofre efetivamente os condicionamentos das relações sociais existentes (GREVE; SALAFF, 2003; MILLER, 2000). Conforme argumenta Filion (1993, p. 59), este sistema de relações é fundamental para a atividade empreendedora, uma vez que,

[...] os empreendedores são originalmente produtos dos sistemas de relações da família, que depois desenvolvem uma rede de relacionamentos empresariais, de modo que as pessoas nela envolvidas se tornam produtos sociais de que o empreendedor precisa, à medida que venham realizar sua visão.

$\mathrm{Na}$ concepção deste autor (FILION, 1993), o suporte familiar é especialmente relevante no início do desenvolvimento da visão empreendedora, o que moldará os tipos de visão inicial que o empreendedor poderá ter na criação de um negócio. Todavia, na constituição e consolidação de uma visão mais ampla, as novas relações que se estabelecem (amigos) são partes fundamentais do processo de formação da visão.

Já com relação ao domínio dos requisitos empreendedores, a literatura pesquisada já parece partir do entendimento de que para empreender é necessário, antes de tudo, dominar algumas habilidades específicas (DOLABELA, 1999; DORNELAS, 2005; CHIAVENATO, 2006; BARON; SHANE, 2007). A sugestão geral dada pelos diversos autores de manuais que se propõem a analisar o empreendedorismo e desenvolver ações empreendedoras é a de que, além de uma idéia bem concebida, os empreendedores necessitam ter domínio de habilidades tais como gerenciar fontes de financiamento e parcerias diversas; promover gerenciamento das atividades cotidianas do negócio; ter disciplina e organização pessoal, entre outros. 
Os tópicos acima apresentados têm como um pressuposto geral potenciais influências sobre o interesse em empreender (ao menos a priori). Entende-se que seja conveniente avaliar a natureza desta influência em contextos específicos (com recortes tais como a região geográfica, área de formação, profissão, fatores étnicos, gênero...). Baughn et al (2006), por exemplo, analisaram os fatores em conjunto, considerando o recorte regional. Para este trabalho, decidiu-se avaliar o recorte por área de formação. Os detalhes desta decisão estão expostos no item seguinte.

\subsection{Desenvolvimento das hipóteses}

Baughn et al (2006) desenvolveram um estudo para avaliar o interesse empreendedor de estudantes de negócios de três diferentes países: China, Vietnam e Filipinas. No trabalho, os autores avaliaram um conjunto de hipóteses associadas aos fatores de influência no interesse dos estudantes em desenvolver atividades associadas ao empreendedorismo, e em seguida testaram estas hipóteses junto a aproximadamente 800 estudantes, distribuídos nos três países.

Para este artigo, considerou-se conveniente que se partisse da proposição desenvolvida por estes autores, e que se desenvolvesse 0 aprimoramento e as devidas adaptações para o contexto brasileiro, e especificamente para os condicionantes do novo contexto de análise. Especificamente com relação às hipóteses, Baughn et al (2006) desenvolveram cinco hipóteses que anunciavam relações de influência para o interesse empreendedor. Estas hipóteses foram avaliadas no seu contexto específico do trabalho original, e foram adaptadas ao contexto e aos objetivos deste artigo. Os detalhes foram os seguintes:

- Primeiramente, Baughn et al (2006) desenvolveram a hipótese de que o interesse empreendedor é condicionado pela vocação e pela cultura nacionais de incentivo e apoio ao empreendedorismo. Os autores partiram de constatações anteriores de que a aceitação, a admiração, ou mesmo o 
incentivo direto promovidos pelos países, são condicionantes do interesse que as pessoas desenvolvem em empreender. Acredita-se, por outro lado, que tal observação é cabível à análise de diferentes áreas de formação profissional. Assim, tomando esta evidência proveniente da análise exploratória, optou-se por adaptar a hipótese do estudo, relacionando não mais a norma nacional, mas a norma do curso. A hipótese definida foi a seguinte:

H1 O interesse empreendedor está positivamente relacionado com a vocação percebida ao empreendedorismo da área de formação;

- Baughn et al (2006) também analisaram a influência do capital social, este entendido como o suporte de familiares e amigos. A hipótese desenvolvida pelos autores foi utilizada aqui sem adaptações, e foi avaliada com o seguinte enunciado:

H2 O interesse empreendedor está positivamente relacionado com o suporte providenciado por familiares e amigos;

- Os autores também desenvolveram uma hipótese diretamente relacionada com a hipótese anterior, que associava o interesse empreendedor à atividade empreendedora de algum membro da família. Para este trabalho, considerou-se relevante avaliar não apenas a condições do membro da família, mas também do próprio estudante. Assim, a hipótese definida foi a seguinte:

H3. O interesse empreendedor é positivamente influenciado pela propriedade de empresa pelo empreendedor ou por seus familiares;

- A quarta hipótese desenvolvida por Baughn et al (2006) também associou a família com o empreendedorismo, e avaliou a relação entre o interesse 
empreendedor e a percepção de que empreender implicaria nas obrigações familiares. Entendeu-se aqui que tal avaliação é compatível com a análise da atitude dos diferentes países em relação à instituição família e às obrigações decorrentes, mas tal atitude não é cabível na análise das áreas de formação de um mesmo país. Assim, especificamente em relação a esta hipótese, entendeu-se que sua aplicação ao contexto de formação, ainda que fosse possível, não era adequada;

- A quinta hipótese de Baughn et al. (2006) relacionava o interesse empreendedor com a auto-avaliação dos respondentes relacionadas ao domínio das habilidades necessárias para o desenvolvimento de ações empreendedoras. Esta hipótese foi mantida para este estudo, e está anunciada como segue:

H4 O interesse empreendedor está positivamente relacionado à percepção de domínio individual das habilidades necessárias para empreender eficientemente.

A partir destas hipóteses, desenvolveu-se um estudo empírico para validação por meio de técnicas estatísticas adequadas. Os procedimentos estão expostos no item seguinte.

\section{Metodologia}

O trabalho foi desenvolvido em três etapas: procedimentos exploratórios; definição do instrumento e coleta de dados; e trabalho empírico. Os procedimentos exploratórios foram desenvolvidos em duas fases: a primeira constou da pesquisa bibliográfica desenvolvida e o desenvolvimento das hipóteses, conforme exposto no item 2; já a segunda fase consistiu nos procedimentos exploratórios gerais, que foram relacionados à avaliação de 
trabalhos semelhantes, análise de escalas utilizadas, e consulta aos especialistas para fechamento dos construtos da pesquisa.

Como forma de acessar as informações empíricas, foi selecionado como instrumento o questionário. Na definição da estrutura do instrumento, foi decidido que este seria dividido em três blocos de questões: o primeiro bloco contendo as variáveis de identificação mais relacionadas ao contexto de análise e intenções futuras; o segundo bloco envolvendo as questões referentes aos construtos de referência do estudo; por fim, o terceiro bloco contemplou a identificação dos respondentes, com questões sobre dados demográficos e socioeconômicos. Especificamente sobre as escalas dos construtos, todas as variáveis foram extraídas e traduzidas de Baughn et al (2006), com algumas adaptações.

A apresentação dos itens no questionário para mensuração dos quatro primeiros construtos foi feita na forma de afirmação, com averiguação do grau de concordância por meio de uma escala de Likert de 5 pontos, na qual 1 indicada discordância total, e 5 indicava concordância total. O quinto construto (propriedade) foi mensurado por meio de uma variável dummy, com 0 indicando não propriedade de empresas, e 1 indicando propriedade. Após a consolidação preliminar do instrumento, este foi submetido a um pré-teste junto a uma amostra de 10 respondentes. Feitos os devidos ajustes, o questionário foi aplicado. Nesta etapa foram delineadas as configurações apresentadas a seguir:

- Universo da pesquisa: foi constituído por alunos dos cursos de Turismo em funcionamento na cidade Fortaleza (Ceará). O tamanho exato deste universo não pôde ser definido;

- Amostra: dado o objetivo da pesquisa de avaliar preliminarmente as hipóteses desenvolvidas, selecionou-se uma amostra de 149 respondentes, de três diferentes instituições acadêmicas, todas de natureza privada;

- Método de coleta: a coleta de dados foi procedida diretamente pelos próprios pesquisadores, a partir do apoio das coordenações de cursos e de alguns professores que viabilizaram a aplicação. 
Os procedimentos estatísticos para os dados coletados no trabalho de campo foram de três tipos: descrição da amostra; análise univariada dos construtos da pesquisa; e análise multivariada, com a avaliação das hipóteses definidas. Todos os procedimentos foram desenvolvidos com o apoio do software SPSS, versão 13.

A descrição da amostra se deu pela apresentação das freqüências das respostas de cada uma das variáveis sobre o curso, sobre as intenções futuras, e das variáveis demográficas e sócio-econômicas. Já na análise univariada, inicialmente foram extraídas as médias e os desvios-padrão de cada uma das variáveis independentemente.

O conjunto de variáveis também foi submetido preliminarmente a uma Análise Fatorial Exploratória, técnica que, segundo informam Hair et al (2005, p. 91), consiste em uma "classe de métodos multivariados cujo propósito principal é definir a estrutura subjacente em uma matriz de dados". A partir desta técnica, foi possível verificar se os itens utilizados no questionário estavam consistentemente associados aos construtos definidos. Após os procedimentos, para cada um dos construtos foi extraído o coeficiente Alpha de Cronbach, índice que permite avaliar a confiabilidade da mensuração dos construtos pelos itens definidos (MALHOTRA, 1999).

Após estes procedimentos, e confirmada a estrutura dos itens na composição dos construtos, foi extraída uma medida geral por construto, com agregação dos escores pela média das entradas dos itens componentes de cada construto, com exceção do construto 'propriedade' (o procedimento de composição das variáveis de cada construto foi realizado conforme as recomendações e os cuidados apontados por Bagozzi e Edwards [1998]).

Adicionalmente, e considerando que as hipóteses supõem relacionamentos entre construtos, decidiu-se avaliar estes relacionamentos por meio da ferramenta Análise de Regressão Múltipla, que viabiliza a avaliação da consistência da relação de influência entre duas ou mais variáveis independentes, e uma variável dependente (MALHOTRA, 1999). Assim, as quatro hipóteses foram testadas tomando-se como variável dependente 0 
construto (agregado) 'interesse', e como variáveis independentes os construtos (agregados) 'suporte', 'domínio', 'normas' e 'propriedade'.

\section{Análise de dados}

\subsection{Descrição da amostra}

A amostra foi composta por estudantes de todos os anos de curso, porém houve uma preferência por alunos da segunda metade do curso ( $3^{\circ} \mathrm{e}$ 40 anos), que somaram $69,6 \%$ do total. Acredita-se que esta opção viabilize uma melhor avaliação dos quesitos de pesquisa, devido à maior experiência dos respondentes com o curso.

Com relação à natureza da instituição de ensino, todos os estudantes foram provenientes de instituições privadas. Esta distribuição é decorrente do fato de, na cidade de Fortaleza, somente instituições privadas oferecerem cursos de graduação do tipo bacharelado em Turismo. Com relação à escola de nível médio, verificou-se que a grande maioria dos estudantes era proveniente de escolas privadas $(75,8 \%)$.

A variável que inquiria acerca da propriedade de empresa por parte do respondente ou de seus familiares apresentou uma porcentagem considerável para o caso afirmativo (com 36,9\% da amostra). Em relação à condição de trabalho, exatamente metade dos estudantes informou não estar trabalhando, e ainda $21,6 \%$ informaram estar trabalhando em meio período, e $28,4 \%$ informaram estar trabalhando em tempo integral.

Inquiridos acerca do futuro profissional a maioria dos estudantes declarou que deseja conseguir um emprego (público ou privado), com 40,3\% dos respondentes. Os que desejam trabalhar em sua própria empresa somaram 38,9\%, e apenas 3,4\% pretendem trabalhar em empresas da família $(17,4 \%$ indicaram 'outros' como resposta ao item). Estes resultados demonstram que o percentual de estudantes que pretende conseguir um emprego é praticamente igual ao percentual daqueles que querem 
empreender, mostrando que o empreendedorismo é uma opção preferencial para os estudantes de cursos da área Turismo.

Especificamente em relação aos estudos, a maioria dos estudantes pretende fazer um curso de especialização $(58,4 \%)$, seguidos dos que pretendem fazer outro curso de graduação $(16,3 \%)$, e dos que têm a intenção de cursar um mestrado (14,3\%) (um total de 10,2\% indicou 'outros' como resposta a esta questão). Os resultados são indicativos do interesse dos estudantes em seguir nos estudos de aprofundamento, especialmente por meio de cursos de pós-graduação, reforçando a tendência de busca de aperfeiçoamento continuado.

Com relação à idade, a grande maioria $(54,4 \%)$ tem até 24 anos $(25,5 \%$ com 'até 21 anos' e 28,9\% 'acima de 21 até 24 anos'), 24,2\% tem 'acima de 24 até 27 anos', e 21,5\% 'acima de 27 anos'. Em relação ao gênero, 27,5\% eram homens contra $72,5 \%$ de mulheres. A amostra ainda era composta de $78,5 \%$ de solteiros contra $13,4 \%$ de casados $(8,1 \%$ informaram 'outros' como resposta).

Com relação à renda familiar os dados apresentaram-se bem distribuídos, com 19,3\% para renda 'até $R \$ 1.000,00$ ', 27,6\% para 'acima de $R \$ 1.000,00$ até $R \$ 2.000,00$ ', $14,5 \%$ com 'acima de $R \$ 2.000,00$ até $R \$$ $3.000,00$ ', 38,6\% 'acima de $\mathrm{R} \$ 3.000,00$ '.

\subsection{Análise dos construtos}

As variáveis de cada um dos construtos foram submetidas à técnica estatística Análise Fatorial Exploratória - AFE, o que permitiu a comparação com a proposta previamente definida e os resultados efetivamente encontrados a partir do trabalho de campo. Nos construtos 'interesse empreendedor', 'suporte familiar e de amigos', e 'vocação percebida na área', a estrutura fatorial gerada manteve a expectativa previamente definida, não tendo havido a necessidade de qualquer procedimento de ajuste.

Especificamente nas variáveis associadas ao 'domínios de habilidades 
empreendedoras', a AFE fez emergir dois fatores distintos das 15 variáveis originalmente operacionalizadas em Baughn et al (2006). A verificação dos sentidos das variáveis indicou que estas se agrupavam de modo a evidenciar em conjunto dois tipos específicos de habilidades, que foram então identificadas por 'domínio de habilidades estratégicas' e 'domínio de habilidades operacionais' (cf. Anexo). Considerando estes resultados, e avaliando o enunciado da hipótese $\mathrm{H} 4$ (O interesse empreendedor está positivamente relacionado à percepção de domínio individual das habilidades necessárias para empreender eficientemente), esta foi então dividida em duas outras, a seguir enunciadas:

H4a O interesse empreendedor está positivamente relacionado à percepção de domínio individual das habilidades estratégicas necessárias para empreender eficientemente;

H4b O interesse empreendedor está positivamente relacionado à percepção de domínio individual das habilidades operacionais necessárias para empreender eficientemente.

A partir destes resultados e destas decisões, as variáveis utilizadas na pesquisa foram agrupadas por construto, e foram extraídas as médias e os desvios-padrão. As variáveis também foram analisadas em sua confiabilidade para representar os construtos. Para tanto, foi selecionado o índice Alpha de Cronbach. O índice foi extraído construto a construto, tendo-se encontrado valores aceitáveis (todos acima de 0,6). Assim, considerando os resultados da estrutura fatorial encontrada, e da confiabilidade extraída, decidiu-se pela composição das variáveis para gerar uma medida geral de cada construto.

Tomando como regra de composição a média dos escores das entradas na planilha correspondentes a cada construto, cinco novas variáveis foram geradas. Os resultados para as médias e os desvio-padrão de cada um dos construtos estão expostos na Tabela 1. 
Tabela 1: Resultados das médias dos construtos

\begin{tabular}{l|c|c}
\hline \multicolumn{1}{c|}{ Construto } & Média & Desvio \\
\hline Interesse pessoal em empreender & 3,70 & 0,89 \\
Vocação percebida na área & 4,27 & 0,63 \\
Percepção de suporte de familiares e amigos & 3,85 & 0,74 \\
Percepção de domínio de habilidades estratégicas & 3,83 & 0,68 \\
Percepção de domínio de habilidades operacionais & 4,09 & 0,59 \\
\hline
\end{tabular}

Fonte: Pesquisa direta

Conforme é possível verificar, as médias dos construtos apresentam valores entre intermediários e altos, sendo a maior média para 'vocação percebida na área' $(4,27)$, e a menor para 'interesse pessoal em empreender' $(3,70)$. Os desvios-padrão podem ser considerados baixos, com exceção do interesse pessoal em empreender, que apresentou um desvio de nível intermediário.

Pelo resultado das médias apresentadas, é possível entender que, na avaliação dos estudantes, os cursos apresentam grande vocação ao empreendedorismo, o que se compreende pela natureza da área de Turismo, e, adicionalmente, os estudantes se sentem bastante seguros quanto às habilidades empreendedoras de nível operacional. Todavia, o interesse pessoal em empreender, o suporte de familiares e amigos, e a segurança no domínio das habilidades estratégicas ficaram com médias em um nível intermediário.

\subsection{Análise de regressão}

As hipóteses definidas para o estudo foram avaliadas através da técnica estatística Análise de Regressão Múltipla, uma vez que esta viabiliza a avaliação da influência simultânea dos fatores definidos. Assim, o construto 'interesse pessoal em empreender' foi colocado na condição de dependente, ao passo que vocação percebida na área, percepção de suporte, domínio das 
habilidades (estas na mesma escala da variável dependente) e empresa própria ou na família (como uma dummy com 0 para não posse, e 1 para posse) foram inseridas como independentes. Para efeito de análise, foi usado o método de regressão enter, que apresenta os resultados de todas as variáveis independentes, quaisquer que sejam os resultados dos testes de hipóteses dos coeficientes.

Os valores do modelo final de regressão estimado encontram-se na Tabela 2. O modelo pôde ser considerado consistente $\left(R^{2}=0,333\right)$, e, como é possível verificar, na avaliação da significância estatística, quatro das cinco dimensões mostraram-se influenciadores consistentes do interesse pessoal em empreender dos estudantes (influência verificada quando $p<0,05$ ).

Tabela 2: Resultados da regressão múltipla

\begin{tabular}{l|c|c|c}
\multicolumn{1}{c|}{ Dimensões } & Coefic. $\boldsymbol{\beta}$ & Estat. t & Sig. \\
\hline Vocação percebida na área & 0,211 & 2,849 & 0,005 \\
Percepção de suporte de familiares e amigos & 0,285 & 3,595 & 0,000 \\
Empresa própria ou na família & 0,145 & 2,009 & 0,046 \\
Percepção de domínio de habilidades estratégicas & 0,255 & 2,654 & 0,009 \\
Percepção de domínio de habilidades operacionais & 0,064 & 0,634 & 0,527 \\
\hline
\end{tabular}

Fonte: Dados da pesquisa

A partir deste resultado, têm-se condições para a análise das hipóteses, conforme procedido a seguir:

- A hipótese $H 1$, que afirmava que 'o interesse empreendedor está positivamente relacionado com a vocação percebida na área de formação', foi aceita $(\beta=0,221, p<0,01)$. Desta forma, tem-se a confirmação de que, para os estudantes de Turismo, quanto mais estes percebem uma orientação do curso para o empreendedorismo, mais estes se interessam por iniciar seu próprio negócio;

- A hipótese H2, que afirmava que 'o interesse empreendedor está positivamente relacionado com o suporte providenciado por familiares e amigos', também foi aceita $(\beta=0,285, p<0,001)$. Nesse caso, compreende- 
se a relevância do apoio de familiares, e especialmente de amigos, algo que é recorrente no próprio desenvolvimento dos cursos, quando colegas se envolvem em projetos em grupo, e podem desencadear a partir disto iniciativas empreendedoras;

- A hipótese H3, que afirmava que 'o interesse empreendedor é influenciado pela propriedade de empresa pelo estudante ou por seus familiares', foi aceita $(\beta=0,145, \quad p<0,05)$. Tal evidência confirma a suposição do condicionamento da propriedade de um negócio na escolha de cursos de Turismo e reforça que a proximidade com um negócio exerce influência no interesse em empreender dos estudantes;

- A hipótese $\mathrm{H} 4 \mathrm{a}$, que afirmava que 'o interesse empreendedor está positivamente relacionado à percepção de domínio individual das habilidades estratégicas necessárias para empreender eficientemente', foi aceita $(\beta=0,255, p<0,01)$. A evidência, nesse caso, foi de que a segurança no domínio das habilidades estratégicas é considerada pelos estudantes da área de Turismo como indispensável ao interessado em empreender, o que se justifica pela associação do ato de empreender com a capacidade de identificar e gerenciar oportunidades de mercado.

- A hipótese H4b, que afirmava que 'o interesse empreendedor está positivamente relacionado à percepção de domínio individual das habilidades operacionais necessárias para empreender eficientemente', foi negada $(\beta=0,064, p=0,527)$. A negação desta segunda hipótese não encontra justificativa a priori, porém informa que os estudantes desta área, a despeito de se considerarem seguros quanto domínio destas habilidades (cf. Tabela 1), não as entendem como um pré-requisito para tomarem a iniciativa de empreender.

De maneira geral, os resultados finais confirmam quatro das cinco 
hipóteses da pesquisa, e informam que o interesse empreendedor dos estudantes de Turismo é seguramente influenciado pela percepção de vocação empreendedora do curso, pela percepção do suporte de amigos e familiares, pela propriedade de empresa, própria ou na família, pelo domínio dos requisitos empreendedores de nível estratégico.

\section{Considerações finais}

Este estudo partiu do pressuposto de que é necessário o desenvolvimento de uma cultura empreendedora na sociedade e em especial nos futuros profissionais, os atuais estudantes de cursos superiores. Acreditase assim que a atividade empreendedora é fundamentalmente fomentadora do desenvolvimento de um país.

O estudo aqui desenvolvido teve a finalidade de analisar um aspecto específico da atividade empreendedora, relacionado à manifestação de interesse dos estudantes de cursos de Turismo em empreender. Analisou-se ainda como este interesse é influenciado pela vocação percebida na área de formação, pela percepção do suporte de amigos e familiares, pela propriedade de empresa e pela percepção de domínio de habilidades empreendedoras, possibilitando assim a compreensão de como estes fatores se manifestam e se relacionam.

De forma geral, os resultados indicaram que os estudantes interessamse medianamente pela atividade empreendedora, que percebem alta vocação da área dos cursos para o empreendedorismo, que percebem um bom suporte de amigos e familiares, e, adicionalmente, que se avaliam como tendo um bom domínio das habilidades necessárias para empreender. Estes resultados são compreensíveis, especialmente devido ao potencial que os cursos da área de Turismo oferecem ao empreendedorismo, a partir da possibilidade de desenvolvimento de novos empreendimentos.

Especificamente em relação às influências sobre 0 interesse empreendedor, foram suportadas quatro das cinco hipóteses definidas. A 
indicação foi de que o interesse empreendedor dos estudantes de Turismo é influenciado pela percepção de vocação empreendedora do curso, pela percepção do suporte de amigos e familiares, pela propriedade de empresa, própria ou na família, pelo domínio dos requisitos empreendedores de nível estratégico, porém não há influência alguma da percepção de domínio das habilidades de nível operacional.

Acredita-se que os resultados permitiram avaliar consistentemente 0 caráter empreendedor de estudantes de Turismo, tendo-se alcançado satisfatoriamente os objetivos definidos. Entende-se assim que as conclusões apresentadas geram conhecimento relevante para os gestores de cursos da área e de instituições que buscam promover a atividade empreendedora (como o poder público, entidades da sociedade civil, e instituições de ensino superior), na medida em que podem contribuir para viabilizar um melhor direcionamento no processo de formação de uma cultura empreendedora nas instituições de educacionais, em especial em cursos ligados à área analisada.

Os resultados do estudo foram limitados, uma vez que a amostra foi restrita a instituições cearenses, além do fato da amostragem ter sido não aleatória. Assim, como recomendação para pesquisa, acredita-se que seria relevante uma replicação deste estudo em outros estados brasileiros, de preferência com métodos de amostragem mais rigorosos. Recomenda-se ainda que este trabalho seja replicado em outros cursos, como Administração, Contabilidade, cursos de tecnologia da informação, dentre outros, e que se proceda a uma comparação para se avaliar as diferenças e similaridades entre os cursos.

\section{Referências}

ANSARAH, M. G. R. Teoria geral do Turismo. In.: Turismo: como aprender, como ensinar. 2 ed. São Paulo: Senac, 2001, p. 11-36.

ARAÚJO, M. H.; LAGO, R. M.; OLIVEIRA, L. C. A. ; CABRAL, P. R. M.; FILION, L. J. O estímulo ao empreendedorismo nos cursos de química: formando químicos empreendedores. Química nova, v. 28, Suplemento, S18-S25, 2005. 
BAGOZZI, R. P.; EDWARDS, J. R. A general approach for representing constructs in organizational research. Organizational Research Methods. $v$. 1, n. 1, p. 45-87, 1998.

BARON, R. A.; SHANE, S. A. Empreendedorismo: uma visão do processo. São Paulo: Thomson Learning, 2007.

BAUGHN, C. C.; CAO, J. S. R.; LE, L. T. M.; LIM, V. A.; NEUPERT, K. E. Normative, social and cognitive predictors of entrepreneurial interest in China, Vietnam and Philippines. Journal of Developmental Entrepreneurship. v. 11, n. 1, p. 57-77, Mar 2006.

BEGLEY, T. M.; TAN, W. The social-cultural environment for entrepreneurship: a comparison between East Asian and Anglo-Saxon countries. Journal of International Business Studies. v. 32, n. 3, p. 537-553, 2001.

BENI, M. Análise estrutural do Turismo. 12. ed. São Paulo: SENAC, 2007.

CHIAVENATO, I. Empreendedorismo: dando asas ao espírito empreendedor. São Paulo: Saraiva, 2006.

DOLABELA, F. Oficina do empreendedor. São Paulo: Cultura Editores, 1999.

DORNELAS, J. C. A. Transformando idéias em negócios. 2. ed. Rio de Janeiro: Elsevier, 2005.

GORINI A. P. F.; MENDES, E. F. Setor de Turismo no Brasil: segmento de hotelaria. BNDES Setorial, Rio de Janeiro, n. 22, p. 111-150, set. 2005.

GREVE, A.; SALAFF, J. Social networks and entrepreneurship. Entrepreneurship Theory and Practice. v. 28, n. 1, p. 1-22, 2003.

FILION, L. J. Visão e relações: elementos para um metamodelo empreendedor. Revista de Administração de Empresas. v. 33, n. 6, p. 50-61, nov-dez 1993.

. Sistemas gerenciais de empreendedores e operadores de pequenos negócios. Revista de Administração de Empresas. v. 39, n. 4, p. 6-20, outdez 1999.

. Carreiras empreendedoras do futuro. Revista Sebrae. Brasília, v. 1, p. 35-51, out-dez 2001.

HAIR, J. F.; ANDERSON, R. E.; TATHAM, R. L. BLACK, W. C. Análise multivariada de dados. 5. ed. Porto Alegre: Bookman, 2005. 
MALHOTRA, N. K. Marketing research: an applied orientation. 3. ed. New Jersey: Prentice-Hall, 1999.

MILLER, N. L. Family microenterprises: strategies for coping with overlapping family and business demands. Journal of Developmental Entrepreneurship. v. 5, n. 1, p. 87-103, 2000.

MURPHY, P. J.; LIAO, J.; WELSCH, H. P. A conceptual history of entrepreneurial thought. Journal of Management History. v. 12, n. 1, p. 12-35, 2006.

SCHUMPETER, J. A. The theory of economic development. Cambridge, MA: Harvard University Press, 1934.

SOUZA, E. C. L.; GUIMARÃES, T. A. (orgs.). Empreendedorismo: além do plano de negócio. São Paulo: Atlas, 2005. 
COSTA, Francisco José da. Fatores de influência no interesse empreendedor: uma análise junto a estudantes de Turismo. Revista Brasileira de Pesquisa em Turismo. v. 2, n. 4, p.4-27, dez. 2008.

\section{Anexo: Médias e desvios-padrão por variável da pesquisa}

Interesse pessoal em empreender

$$
\text { Variáveis }
$$

É muito provável que eu abra meu próprio negócio nos próximos 5 anos

Se eu abrir um novo negócio, é muito provável que tenha sucesso

Para mim, é muito desejável abrir um negócio próprio

Começar um negócio é uma idéia muito atraente para mim

Seria fácil para mim abrir meu próprio negócio

\begin{tabular}{|c|c|c|}
\hline Variáveis & Média & Desvio \\
\hline É muito provável que eu abra meu próprio negócio nos próximos 5 anos & 3,57 & 1,29 \\
\hline Se eu abrir um novo negócio, é muito provável que tenha sucesso & 3,91 & 1,16 \\
\hline Para mim, é muito desejável abrir um negócio próprio & 4,03 & 1,22 \\
\hline Começar um negócio é uma idéia muito atraente para mim & 3,95 & 1,18 \\
\hline Seria fácil para mim abrir meu próprio negócio & 3,04 & 1,16 \\
\hline \multicolumn{3}{|l|}{ Vocação percebida na área } \\
\hline Variáveis & Média & Desvio \\
\hline $\begin{array}{l}\text { O pensamento criativo é visto como um caminho para o sucesso na minha } \\
\text { área de formação }\end{array}$ & 4,58 & 0,97 \\
\hline $\begin{array}{l}\text { As pessoas na minha área de formação valorizam aqueles que abrem seu } \\
\text { próprio negócio }\end{array}$ & 3,59 & 1,13 \\
\hline $\begin{array}{l}\text { Transformar uma boa idéia em um negócio é bem visto na minha área de } \\
\text { formação }\end{array}$ & 4,47 & 0,90 \\
\hline O empreendedorismo é admirado na minha área de formação & 4,44 & 0,87 \\
\hline
\end{tabular}

\section{Suporte familiar e de amigos}

\section{Variáveis}

Se eu abrisse um negócio, alguns membros de minha família trabalhariam comigo

Se eu abrisse meu próprio negócio, os membros de minha família me ajudariam

Minha família aprovaria a idéia de eu abrir meu próprio negócio

Se eu abrisse meu próprio negócio, alguns de meus amigos trabalhariam comigo

Se eu abrisse meu próprio negócio, meus amigos me ajudariam

Meus amigos aprovariam se eu abrisse meu próprio negócio

\begin{tabular}{c|c} 
Média & Desvio \\
\hline 3,42 & 1,19 \\
4,07 & 1,12 \\
4,24 & 1,04 \\
3,62 & 1,10 \\
3,53 & 1,21 \\
4,14 & 1,02 \\
\hline
\end{tabular}

\section{Domínio de habilidades estratégicas}

Variáveis

Tenho capacidade de identificar fontes de capital para um negócio

Sou capaz de desenvolver relacionamentos com possíveis fontes de

financiamento

Tenho capacidade de reagir a mudanças ambientais, em tempo hábil

Sei identificar e avaliar informações de mercado para um novo negócio

Consigo entender os aspectos legais associados a um novo negócio

Tenho condições de criar produtos que atendam as demandas dos clientes

Tenho facilidade em identificar oportunidades para futuros negócios

\section{Domínio de habilidades operacionais}

\section{Variáveis}

Consigo trabalhar produtivamente em situações estressantes

Tenho capacidade de me comunicar adequadamente com outras pessoas

Tenho condições de gerenciar um fluxo de caixa

Sou capaz de promover venda pessoal

Sou hábil em gerir meu tempo produtivamente

Tenho capacidade de gerenciar riscos eficientemente

Eu consigo ser persistente, mesmo em situações adversas

Tenho capacidade de desenvolver ações de planejamento de negócios

Média $\quad$ Desvio

$3,60 \quad 0,91$

$3,89 \quad 1,03$

$3,99 \quad 1,04$

$3,77 \quad 0,94$

$3,61 \quad 0,96$

$4,00 \quad 1,00$

\begin{tabular}{l|l}
3,93 & 0,87 \\
\hline
\end{tabular}

Recebido em: março de 2008

Aprovado em: outubro de 2008 